BENTHAM OPEN
CrossMark
Content list available at: www.benthamopen.com/TOPSYJ/
DOI: $10.2174 / 1874350101811010148,2018,11,148-162$

RESEARCH ARTICLE

\title{
Visit to an Unknown City: Exploring Children's Fictional Narratives About a Tourist Experience
}

\author{
Roberta Della Croce, Benedetta Elmi, Chiara Fioretti and Andrea Smorti \\ Department of Educational Sciences and Psychology, University of Florence, Via di San Salvi, 12 - Padiglione 26, \\ 50100 Firenze, Italy
}

Received: May 4, 2018

Revised: July 20, 2018

Accepted: August 2, 2018

\section{Abstract: \\ Background:}

Children have an important role in the decision making process about travels. However, research about children in tourism is still lacking. Although scholars have investigated memories of trips, imagination and expectations on visiting new places that have not yet been explored.

\section{Objective:}

To explore children's narratives about visiting an unknown city.

\section{Methods:}

Fifty-nine third grade 7-to-8-year-old children took part in the study. Children were asked to write a story on the visit to an unknown city starting from a given stem.

\section{Results:}

Two types of stories emerged from children's narrations: likelihood and non-likelihood stories. The latter were characterized by the presence of complicating actions and resolutions, villain characters, fight and achievement and were rich in typical elements of fairy tale story. Likelihood stories were characterized by the presence of play and exploration activities, parents characters and the return to home. These type of stories mainly lack complicating action, resolutions and verbal interactions. Finally, these narrations do not show dramatic features as fantasy stories. The lexical analysis of emotions revealed that non-likelihood stories show more negative affective words than likelihood ones.

\section{Conclusion:}

Results make an important contribution to research on children's narratives about travel, highlighting children's imagination and expectations on the travel experience and providing an analysis of their representations.

Keywords: Child tourism, Imagination, Autobiographical memory, Fictional narratives, Tourism experience, Storytelling, Children development, Language development.

\section{INTRODUCTION}

Family tourism and the role of children in tourist choices and experiences is a recent field of research. Although the scientific literature has investigated tourism usually by means of a single individual's experience or travel groups, some authors [1] have started to consider a new dimension: family.

\footnotetext{
* Address correspondence to this author at the Department of Educational Sciences and Psychology, University of Florence, Via di San Salvi, 12 -
} Padiglione 26, 50100 Firenze, Italy; Tel: 0039-055275026; E-mail: Andrea.smorti@unifi.it 
This change might be attributed to the parents' and teachers' rising requests for tourist services for children. Research on marketing and consumer behaviour defined children as active and expert tourist consumers, able to substantially influence the process of their parents' decisions [2, 3]. Given the fact that tourist activities are performed during leisure time, it's important to underline that empirical studies show that holidays contribute to positive familiar functioning as well as to the communication and cohesion amongst family members [4]. Therefore, a tourist experience may have a cohesive function for the family. Although various studies suggest the importance of the role of children in the decision of tourist destinations, children are almost absent in the psychological research on tourism $[5,6]$. The few studies conducted are mainly focused on memories about trips and or tourist visits with parents and school [7,8] and have considered the role tourism has in learning activities. The need for studies investigating how children interpret travel experiences becomes obvious. The theme of travel is deeply linked to other typical childhood themes, such as curiosity, discovery and adventure. Travelling is considered as an instrument to learn about the environment and to give the world a personal meaning. Above all, travelling is strictly linked to narration.

Some narrative genres [9] have the structure of a journey and through the act of narration, travelling acquires a starting phase, high points, troubles and finally a resolution (going back home).

Generally, people use narration as a tool for making meaning and to give a sense to their own experience. Like Jerome Bruner [10] emphasized in his studies on narrative Psychology, "the central concept of a human psychology is meaning, and the process and transactions involved in the construction of meaning" [10]. The child's improvement in narrative skills is "not simply a mental achievement, but an achievement of social practice that lends stability to a child's social life" [10]. The travel theme is deeply connected to stories and narrations and children already master this kind of language at an early age. Children are exposed to many stories where the characters have to go on a long journey, taking on new challenges and living incredible adventures.

An overlap can be found in the relation between travel and narration [11]. Travel acquires linguistic features through narrative, and vice versa, narration can be considered a journey. Besides this, narratives draw from travelling inspiration for their plots. Thus, between the two issues, there is a structural similarity that it is unique in this kind of expressive activity.

To conclude, studies on children's tourism experiences are focused on autobiographical memories of journeys, and narrative seems to be the tool people use to share their travel experiences.

\subsection{Narrating Autobiographical or Fictional Stories about a Journey}

As discussed in the previous paragraph, autobiographical memories regarding children's tourism activities have been explored by means of children's accounts of their experiences [7, 8]. However, there are currently no studies investigating children's fictional narratives about journeys. This issue could address important information on the topic of children and tourism. In fact, scientific literature underlines that personal and fictional narratives are different in terms of linguistic and structural characteristics.

Children are supported by significant adults in producing personal narratives from the very early years of life [12]; for this reason, studies on children's narrative skills pointed out that they are prone to producing better-structured narratives when telling about personal events rather than when they have to create stories starting from fiction [13].

In effect, scholars [13] argued that fictional and personal narratives are different and place different demands on the narrator, since the latter may be more easily produced because of the narrator's familiarity with the events and characters in the story. Hudson and Shapiro, for instance, underlined that personal narratives are usually richer than fictional ones, in terms of information on the setting and the protagonists of the story. Conversely, fictional narratives require an expressive elaboration of information used to create a story. Ukrainetz and colleagues [14] argued that narrating 'made-up' stories deals with the need to tell charming or funny stories, with a goal-oriented and problem-resolution structure.

Conversely, research underlined that people tend to organise fictional stories and individual experience by means of the same scripts $[15,16]$. In these studies, participants were asked to generate stories starting from some emotional cues with the aim to observe possible comparisons between fictional stories and autobiographical memories. Results showed that people tend to interpret emotional cues by means of their autobiographical memories. In other words, fictional narrations and autobiographical memories start both from emotional and biographical cue, but while the latter are "recounts of real past experience" [13], the former entail the need to perform an interesting story, fulfilling the listener's expectation, by means of a creative elaboration of reality. 
As we have seen, fictional narratives deal with the combination of creative activities and reality elaboration processes. It can be theoretically useful referring to the well-known Vygotskian distinction in human mental activity, between reproductive and creative or combining functions [17]. The reproductive function, which is linked to memory, allows human beings to reproduce a certain behaviour or to make use of prior knowledge. The combining function alternately creatively reworks previous knowledge, facilitating the creation of new behaviours and ideas. It's an important quality of the human mind to combine and reconnect creatively, the elements of past experiences, making use of them to create something new. This creative activity is called by Vygotsky, 'imagination' [17]. Imagination, then, is a constitutive part of human thought and does not refer only to the creation of bizarre fantasies or something that does not correspond to reality [18]. Creative processes are already present in children and can especially be seen in their play activities and are especially identifiable in the symbolic play [19, 20]. Made-up stories are an example of creative processes and play in children [17]. In the process of story creation, children use elements already known, and mix them to create something new.

Instead, the reproduction of something that the child lived or seen is the basis of personal narratives. The elements of the known are also present in fictional narrative, but are mixed in a creative way, that belong to the child himself/herself. In the story construction, the child is asked to choose the type of elements to insert and how to mix them. We can easily understand how fictional narratives can differ on the basis of the child's "taste" and ability to mix known elements. Some made-up stories can be more bizarre, whereas others are more realistic.

In story construction, we can observe then either reproductive or creative processes [17]. Indeed, in the study of autobiographical memories, researchers have pointed out that the elaboration of past experience is often connected with possible events that occurred [21, 22]. In this sense, studying personal memories cannot be separated from the imagination of a possible world.

In the expressive and creative process, children adapt their narratives to a canonical plot internalised in cooperative discussions with significant adults from early childhood [23, 24].

As Labov suggested in his theory of narrative plot and analysis [24], narratives have two main functions: reference and evaluation. Referential information is an orientation that the narrator provides in order to describe details concerning conditions, persons, or objects involved in the story. Evaluative information aims to explain why the story is meaningful and therefore interesting to tell. In fact, narratives are structured around high points, defined as the point of the story where a complication appears fulfilling expectation and catching the listener's attention. Complication, and consequently, the resolution, are the core of the narration and provide information on the reason why the narrator believes that the story is important to narrate.

Studies in the field of developmental Psychology underline that at the age of seven to eight children will usually include in the story an event that gives a turning point to the plot, as a problem to be resolved. Authors suggest that this kind of complication is generally based on knowledge about things that can go wrong, particularly regarding social interactions. Some studies $[25,26]$ found that six-year-old children's narratives are rich in references to psychological causality, as explicit and implicit intentions, emotions and directives.

Furthermore, fictional stories are usually organised in specific categories and content, which are: harmony and peace, conflict and threat, amusement, foreign land, supernatural power, travel, sensorial pleasure, royalty, technology; wherein harmony and peace between nature, animals and other humans seem to be the most frequent category [27]. "Travelling" seems to be a frequent topic in children's fictional stories: they travel to all kinds of possible and fantasy destinations, whereby not only the destination itself but also the way to get there and the company of loved ones, seem to be of high importance. On the basis of examined literature on children's narratives, we can conclude that children use two main styles to represent their experience. According to the first style, experiences are narrated on the basis of memories that are recalled in the moment of narrating. Therefore, the narrative appears more realistic and closer to the laws of the natural and social world. According to the other style, experiences are narrated putting them in a fantasy world and following the imagination of the narrator. These are more play-like narratives and are closer to folk tales, with monsters and villains to fight. The reported studies suggest that children's' narration is spontaneous, able to give space to fantasy and imaginary worlds, and at the same time is deeply influenced by knowledge and the narrator's personal experiences. In other words, a child creates a fictional story by negotiating between the consolidated and the possible [28].

In investigating children's narratives about journey experiences, the analysis of the story's structure provides important information on the experience children perceive as "tellable" and meaningful, therefore scholars could collect 
specific data from narratives, on what children imagine about their journeys. Furthermore, investigating fictional narratives of journeys, rather than personal narratives of memories could address important knowledge regarding children's expectations about travelling to an unknown place, providing information to create specific tourism services tailored on their needs and expectations.

\section{MATERIALS AND METHODS}

The main purpose of this work is to shed light on the elements that characterise fictional narratives about the exploration of an unknown city, produced by 7 and 8 -year-old children.

One goal of this exploratory research was to study both realistic and imaginative aspects connected to children's representation of a tourist visit to a city. Therefore, the aim of this study was to explore the child's representation, connected to the discovery of a new city, in order to better comprehend children's needs and expectations connected to the travel experience.

Since, as suggested in the previous paragraph, the travel issue is deeply connected with stories and narratives, we decided to explore how children imagine a travel experience asking them to perform a narrative about a fictional experience in an unknown place. Specifically, we asked children to construct a story starting from an appropriate stem. Indeed, as it is well known, this technique is traditionally used with children in the evaluation of unconscious aspects. Unconscious aspects may be stimulated in narratives through the use of the third person and through the insertion of not precisely defined places and characters. A large research tradition on projective tests confirms the benefit of this method [29], which can also be used in a non-projective context, enabling the exploration of mental representations (e.g. travel representation), connected someway to the unconscious.

To reach the goal of the present study, the children's style of narrating a visit of an unknown city has been assessed, as well as the main features of the narrated stories.

In line with the scientific literature discussed in the previous paragraphs, we hypothesised that children narrate their fictional visit according to two main styles, likelihood and unlikelihood and that these two styles constitute two possible points of view, representing different orientations in children's thoughts. Given the explorative design of this study, we were interested in analysing these two different representations in order to draw suggestions for the creation of specialised tourist services, tailored to children's needs, imaginative and cognitive characteristics.

\section{EXPERIMENTAL DESIGN}

\subsection{Participants}

Fifty-nine third grade 7-to-8-year-old children (25 girls, 33 boys) took part in the present study. All children were students of a school in the district of Florence. Only one child was excluded because he did not follow the research procedure during data collection.

We selected this specific age range because scientific literature reports that children are able to properly write a story, which was our research request, and to recall past tourist experiences. At the same time children aged 7 and 8 years old are already in contact with the typical narrative genres of the childhood world, both classical, like fairy tales, and modern, typical of contemporary television shows. At this age, it is therefore possible to observe a well-organized reality comprehension and imagination process, influenced by the use, in the story's production, of narrative genres like those of adventure, exploration or discovery.

\subsection{Procedures}

In a preliminary phase, with the purpose of presenting the research and its aims, researchers made contact with the School Principal and with teachers willing to collaborate. Afterward, information about family, and school trips to visit other cities were collected from the teachers and three classrooms in which both families and school visiting experiences had been organised. Moreover, in the selected classes no child's learning disabilities were presented. Lastly, the informed consent form was delivered to the families and subsequently given back with the children's parents signature.

The research took place in the school classrooms, during school time and in the presence of the teachers. After the explanation to the students about the research aims, each child received a foolscap and researchers asked them to write a story starting from a given stem. The stem was orally read by researchers and also written in the first page of the 
foolscap. It was the following: " Once upon a time, there was a brave and curious child. He had always lived in the same city and he really wanted to visit another city of which he always heard people talking about. One day he decided to leave, and he called his friend to go together. They walked and walked and finally they arrived in that city. They crossed a big door and...".

At this point children were asked to continue the story creating a fictional narrative. It was specified that the main character of the story could be a boy or a girl. To perform the task no other information or time limits were given. Waiting for everyone to finish the task, the children could conduct other silent chosen activities. In general, the children didn't take more than two hours to finish the narrative task.

\section{MEASURES}

The children's narratives have been examined through three different analysis procedures: content analysis, structural analysis and lexical analysis of emotional words. Through the content analysis we investigated the themes present in the texts, namely semantic aspects. This analysis can shed light on the way in which children imagine visiting a city. Through the structural analysis we explored the way in which children organise and tell stories about their visit to an unknown city. By means of the analysis of emotional words, we counted the words used in the story that express affective processes involved in the visit.

\subsection{Content Analysis}

For the content analysis, we were inspired by the works of different researchers [30 - 34]. We used a grid analysis of the qualitative variables of the text, that were evaluated in terms of presence-absence.

Type of stories:

- "Likelihood narratives": all the story's elements are realistic and plausible in reference to the state of the real world (e.g. visiting an unknown city characters meet a citizen helping them to find a hotel to sleep in);

- "Unlikelihood narratives": some aspects of the story can be attributable to a possible world different to the real one (e.g. characters meet a wolf speaking and dancing).

Descriptive elements:

- "Descriptive stories": the story is filled with descriptive elements, as detailed descriptions of places or actions independently of the realistic or fantasy connotation of the story;

- "Non-descriptive stories": the story lacks details.

Obstacles:

- Danger: threats on the life or security of the characters;

- Accomplishments: winnings and goals achieved by the characters.

Type of characters:

- Villain characters: evil or threatening characters;

- Anthropomorphic animal characters: animals with human characteristics (e.g. talking rabbit);

- Fairy-tale characters: characters typical of fairy-tales (e.g. gnomes or princess);

- Friends: characters that are friends of the protagonist;

- Parents: characters that are parents of the protagonist.

Character's actions:

- Play: characters are engaged in play and fun activities;

- Food: characters eat;

- Exploration: characters explore the environment;

- Travel: characters move from one place to another;

- Back home: characters return back home after having been away for a while; 
- Sleep: characters go to sleep.

Environment:

- Desired places: in the description places are mentioned such as playgrounds or candy shops;

- Beauty: the beauty of the place is mentioned;

- Positive climate: presence of positive climatic conditions (e.g. sun);

- Negative climate: presence of negative climatic conditions (e.g. storm).

\subsection{Structural Analysis}

In the structural analysis, we took inspiration from different research [24, 33, 35]. Starting from these studies, we designed a set of items aimed at establishing the presence or absence, in the texts, of the following structural elements:

- Complicating actions: number of problematic events that lead to an evaluative high point;

- Resolution: resolutive events following the high point.

After a preliminary analysis on the sample, we established that "Complicating actions" and "Resolution" were always put together. For this reason, we decided to consider them as a unique category named "Complicating action resolution";

- Coda: part of the narrative aimed to close the story. Coda can be both long or short and represent the end of the story;

- Evaluation: part of the narrative in which the storyteller's point of view, on the story elements, comes out;

- Orientation: this traditional category [36] describe the main elements that constitute the setting of the story such as a description of place, time, etc.

- Direct speech: on the base of evidence [37] we considered the presence of direct speech as the presence of a high point in the story.

Before applying this analysis, we conducted the scale's reliability evaluation. Two independent judges evaluated separately 20 narratives, randomly selected from data collected. The Cohen's Kappa value was then calculated and resulted as excellent for all the scale's items $(\mathrm{K}>.80)$.

\subsection{Lexical Analysis of Emotion Words}

The lexical analysis of emotional words is aimed at identifying the text words related to emotions. For this aim, we used LIWC software [38, 39]. We, therefore, identified those words connected to emotion and specifically those words linked to "positive feelings" (e.g. wellness), "positive emotions" (e.g. happiness), "optimism" (e.g. pride), "negative emotions" (e.g. hate), "anxiety" (e.g. tension), "anger" (e.g. angry) and "sadness or depression” (e.g. cry).

\section{RESULTS}

\subsection{Story Analysis: Content, Structure and Emotional Words}

Tables 1 and $\mathbf{2}$ show the frequency and the percentages of all items referring to the content (Table 1) and the structure (Table 2 ) of the story.

Table 1. Frequency analysis of the content elements.

\begin{tabular}{|c|c|c|}
\hline Content Analysis & f & $\mathbf{\%}^{\mathbf{1}}$ \\
\hline Type of stories & & \\
\hline Unlikelihood narratives* & 26 & 45 \\
\hline Likelihood narratives & 32 & 55 \\
\hline Descriptive elements & & \\
\hline Descriptive stories & 40 & 69 \\
\hline Not descriptive stories & 18 & 31 \\
\hline Obstacles & & \\
\hline
\end{tabular}


(Table $\square$ ) contd.....

\begin{tabular}{|c|c|c|}
\hline Content Analysis & f & $\%^{1}$ \\
\hline Danger & 19 & 32 \\
\hline Accomplishments & 24 & 41 \\
\hline \multicolumn{3}{|l|}{ Type of characters } \\
\hline Villain characters & 16 & 27 \\
\hline Anthropomorphic animal characters & 8 & 13 \\
\hline Fairy-tale characters & 17 & 29 \\
\hline Friends & 30 & 51 \\
\hline Parents & 18 & 31 \\
\hline \multicolumn{3}{|l|}{ Characters's actions } \\
\hline Play & 21 & 36 \\
\hline Food & 22 & 37 \\
\hline Exploration & 23 & 39 \\
\hline Travel & 30 & 51 \\
\hline Back home & 28 & 48 \\
\hline Sleep & 11 & 19 \\
\hline \multicolumn{3}{|l|}{ Environment } \\
\hline Desire's places & 33 & 56 \\
\hline Beauty & 19 & 32 \\
\hline Positive climate & 8 & 13 \\
\hline Negative climate & 5 & 8 \\
\hline
\end{tabular}

Table 2. Frequency analysis of structural elements.

\begin{tabular}{|c|c|c|}
\hline Structure Analysis & f & \% \\
\hline Complicating action-resolution & 22 & 37 \\
\hline Coda & 34 & 58 \\
\hline Evaluation & 39 & 67 \\
\hline Orientation & 42 & 72 \\
\hline Direct speech & 28 & 48 \\
\hline
\end{tabular}

Considering only percentages above $50 \%$ at the level of content analysis (Table 1 ), stories were characterised by the presence of protagonist's friends (51\%), by the character's movements from one place to another $(51 \%)$ and by accurate descriptions of places, "descriptive stories" (69\%), with a main focus on those places considered to be typically liked by children (56\%), such as parks or sweet shops. The likelihood narratives (55\%) and the unlikelihood ones, were almost equally produced by the children. From further analysis, we found that both the types of stories were equally descriptive. Indeed, unlikelihood narratives were descriptive in $69.2 \%$ of the cases, whereas likelihood narratives were descriptive in $68.8 \%$ of the situations. Even if it is not above $50 \%$, it was found that, in many cases, stories comprised real or figurative fights, aimed at achieving triumph or reward (41\%) and in $48 \%$ of the story, characters returned back home after having been away for a while (e.g. "And the children returned back home, and a child brought away three golden coins, one for each child").

From structural point of view, (Table 2) stories were characterised by the large amount of all the elements that make a story a "good story". In fact, in the $58 \%$ of the stories, there was a "Coda", which was often represented by the classical "and they lived happily ever after". In the $67 \%$ of the cases narratives showed evaluative comments (e.g. "The brave Mollicino") and in $72 \%$ of the situations, orientation elements were present, such as for instance, information connected to the temporal orientation of the story (e.g. "It was early morning..."). It was also noticeable that in almost half of the cases $(48 \%)$ stories were enriched by the presence of direct speech.

The lexical analysis of the emotional words of the stories (Table 3) showed that children made a large use of words connected to positive feelings, in fact the mean number of positive feelings words was $2.1(\mathrm{SD}=1.3)$, whereas the mean of negative emotion words was $0.67(\mathrm{SD}=.73)$. 
Table 3. Analysis of the emotions.

\begin{tabular}{|c|c|c|}
\hline Lexical Analysis of Emotion Words & M & DS \\
\hline Positive feelings & 2.1 & 1.3 \\
\hline Positive emotions & .38 & .58 \\
\hline Optimism & .31 & .57 \\
\hline Negative emotions & .67 & .73 \\
\hline Anxiety & .11 & .27 \\
\hline Anger & .25 & .52 \\
\hline Sadness or depression & .22 & .41 \\
\hline
\end{tabular}

\subsection{Comparison Between Likelihood and Unlikelihood Narratives}

As previously stated, children wrote stories in two different "styles". Some children wrote a likelihood story (32 children, equivalent to $55.2 \%$ of the sample) whereas others wrote an unlikelihood story (26 children, equivalent to $44.8 \%$ of the sample). We did not find any difference between males and females on this variable.

Our starting point was to explore both likelihood and unlikelihood aspects connected to the visit of an unknown city. The likelihood aspects represented the personal experience side and the unlikelihood elements, as components of the imaginative processes. For this reason, we compared the content and structural elements of these two types of story using a U-Man Whitney test.

Table 4 shows the frequency, percentage and results of the U-Man Whitney test of the content and structure, compared in the two kinds of stories: unlikelihood and likelihood. The comparison showed that, for the content, unlikelihood narratives are significantly $(p<.05)$ more characterised by the presence of "danger" $(53.8 \%)$, "villain characters" (50\%), "anthropomorphic animal characters" (26.9\%) and "fairy-tale characters' elements" (50\%). Whereas likelihood narratives showed more, but not significantly, "play" (46.9\%), "back home" (59.4\%), "parents" (40.6\%) and "exploration" $(50 \%)$ elements. Consistent with the results of the content analysis, the structural results showed that unlikelihood narratives were richer in terms of "complicating-action elements" $(p<.05)$.

Table 4. Comparison between likelihood and un-likelihood narratives of the content and structural element.

\begin{tabular}{|c|c|c|c|c|}
\hline- & \multicolumn{2}{|c|}{ Likelihood Narratives } & \multicolumn{2}{|c|}{ Unlikelihood Narratives } \\
\hline- & $\mathrm{f}$ & $\%$ & $\mathrm{f}$ & $\%$ \\
\hline \multicolumn{5}{|l|}{ Content Analysis } \\
\hline \multicolumn{5}{|l|}{ Descriptive Elements } \\
\hline Descriptive stories & 22 & 68.8 & 18 & 69.2 \\
\hline \multicolumn{5}{|l|}{ Obstacles } \\
\hline Danger & 5 & 15.6 & 14 & 53.8 \\
\hline Accomplishments & 11 & 34.4 & 13 & 50 \\
\hline \multicolumn{5}{|l|}{ Type of Characters } \\
\hline Villain characters & 3 & 9.4 & 13 & 50 \\
\hline Anthropomorphic animal characters & 1 & 3.1 & 7 & 26.9 \\
\hline Fairy-tale characters & 4 & 12.5 & 13 & 50 \\
\hline Friends & 16 & 50 & 14 & 53.8 \\
\hline Parents & 13 & 40.6 & 5 & 19.2 \\
\hline \multicolumn{5}{|l|}{ Characters's Actions } \\
\hline Play & 15 & 46.9 & 6 & 23.1 \\
\hline Food & 13 & 40.6 & 9 & 34.6 \\
\hline Exploration & 16 & 50 & 7 & 26.9 \\
\hline Travel & 17 & 53.1 & 13 & 50 \\
\hline Back home & 19 & 59.4 & 9 & 34.6 \\
\hline Sleep & 8 & 25 & 3 & 11.5 \\
\hline \multicolumn{5}{|l|}{ Environment } \\
\hline Desire's places & 16 & 50 & 17 & 65.4 \\
\hline
\end{tabular}


(Table $\square$ ) contd.....

\begin{tabular}{|c|c|c|c|c|}
\hline- & \multicolumn{2}{|c|}{ Likelihood Narratives } & \multicolumn{2}{|c|}{ Unlikelihood Narratives } \\
\hline Beauty & 11 & 34.4 & 8 & 30.8 \\
\hline Positive climate & 5 & 15.6 & 3 & 11.5 \\
\hline Negative climate & 3 & 9.4 & 2 & 7.7 \\
\hline \multicolumn{5}{|l|}{ Structure analysis } \\
\hline Complicating action-resolution & 8 & 25 & 14 & 53.8 \\
\hline Coda & 19 & 59.4 & 15 & 57.7 \\
\hline Evaluation & 22 & 68.8 & 17 & 65.4 \\
\hline Orientation & 22 & 68.8 & 20 & 76.9 \\
\hline Direct speech & 15 & 43.8 & 14 & 53.8 \\
\hline
\end{tabular}

\subsection{Cluster Analysis}

In order to further compare the two types of story (unlikelihood and likelihood) we ran a cluster analysis in order to reduce the number of variables, gathering them in larger dimensions. The graphic, number one, presents the results of the cluster analysis, run with the Ward method, showing the cluster combination distance with modified scale.

Content and structural variables of the research were entered into the cluster analysis. It should be noted that we did not consider in the cluster analysis items with a frequency percentage under $20 \%$.

Results showed that clusters under the cut-off level 8 were 6 (Graphic 1). The first cluster included 4 items: "villain characters", "danger", "complicating action-resolution" and "accomplishments". The second cluster included two items: "fairy-tales characters" and "direct speech". The third cluster included three elements: "coda", "evaluation" and "orientation". The fourth included three elements: "exploration", "beauty" and "descriptions". The fifth included three items that are "back home", "travel" and "parents". The last cluster included the items "food", "play" and "desired places".

\begin{tabular}{l} 
Danger \\
VillainCharacters \\
Complicating ActionResolution \\
Accomplishments \\
DirectSpeech \\
FairyTalesCharacters \\
Coda \\
Evaluation \\
Orientations \\
Exploration \\
Beauty \\
Descriptions \\
BackHome \\
Parents \\
Travel \\
Play \\
Food \\
DesiresPlaces \\
\hline
\end{tabular}

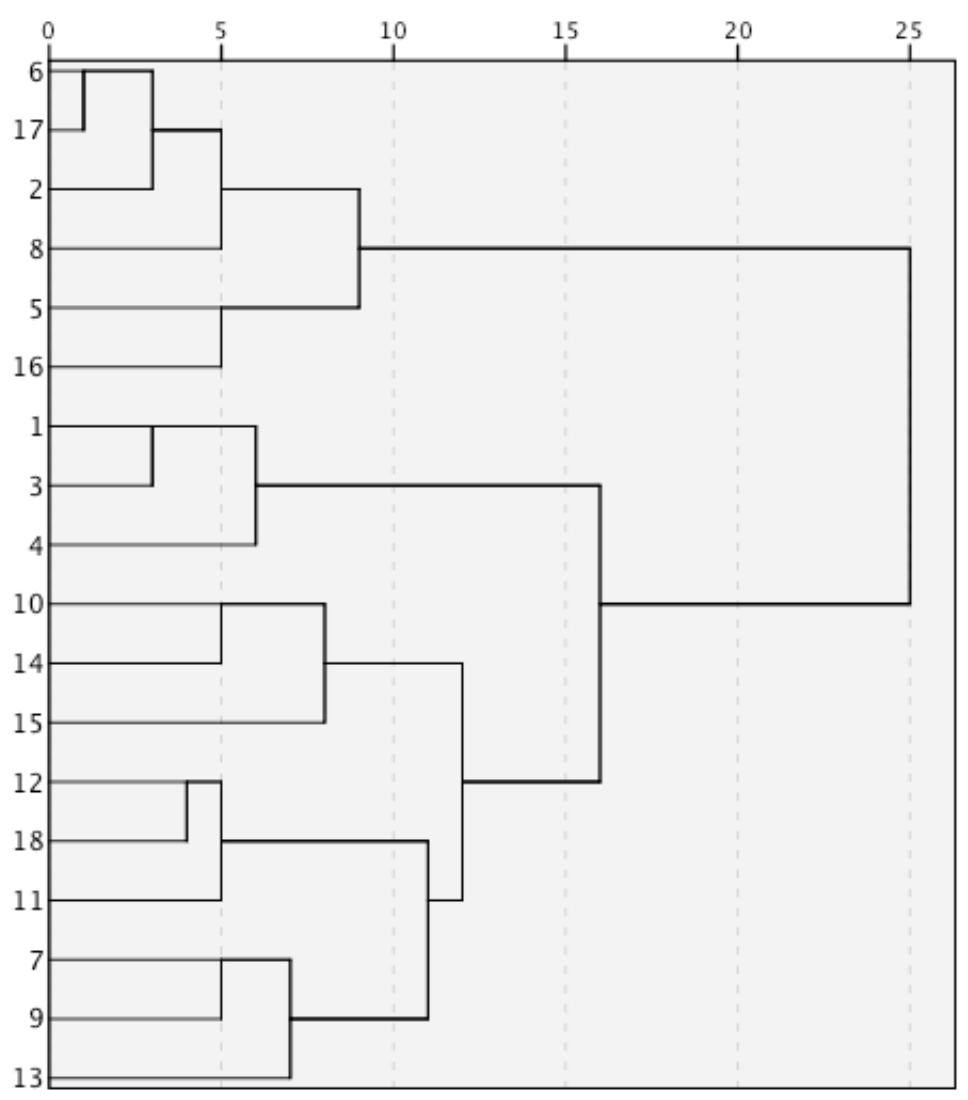

Graphic (1). Cluster analysis. 
Exploring in detail, the relation between the items present in each cluster, by means of contingency tables, the first cluster's items "villain characters", "danger", "complicating action-resolution" and "accomplishments" had strong links. "Villain characters" occurred together with "danger" in $84.2 \%$ of the narratives, with "complicating action - resolution" appearing in $87.5 \%$ of the cases, and with "accomplishments" in the $75 \%$ of the narratives. "Danger" appeared with "complicating actions-resolution" in $89.5 \%$ of the cases and with "accomplishments" in 73.7\%. "Complicating actionresolution" appeared with "accomplishments" in $77.3 \%$ of the cases. This cluster could be considered a model of the story based on problematic and dangerous states, where the protagonist triumphs at the end.

The second cluster elements, "fairy-tale characters" and "direct speech", appeared together in $76.5 \%$ of the narratives, and for this reason, the cluster can be named "verbal interaction".

The third cluster's elements, "evaluation", "orientation" and "coda", were in a strong positive relation, indicating that this was a cluster concerning the narrative structure. "Evaluation" appears with "orientation" in $82.1 \%$ of the narratives and with "coda" in $79.5 \%$ of cases. "Orientation" co-occurred with "coda" in $64.3 \%$ of the cases.

In the fourth cluster, "exploration" co-occurred with "descriptions" in $87 \%$ of cases, whereas the (positive) relations with "beauty" (52.2\% of the situation) was weak. The connection between "beauty" and "descriptions" was positive. In fact, these elements occurred together in $84.2 \%$ of the data collected. This cluster concerned the descriptive part of the travel experience and for this reason, it has been named "explorative-descriptive".

The fifth cluster was characterised mostly by the positive relation between "travel" and "back home" (70\% of cooccurrence) leading us to nominate this cluster "return". The relation between "travel" and "parents" was slightly negative, in fact, these two elements only appeared together in the $46.7 \%$ of the narratives, whereas there was a positive connection between "parents" and "back home" (83.3\%).

Lastly, the sixth cluster exhibited a positive connection between "play", "food" and "desired places" shedding light on the pleasant part of the travel experience. For this reason, we nominated this cluster "travel's pleasures". "Play" cooccurred with "food" in $61.9 \%$ of the narratives, and with "desired places" in $76.2 \%$ of the cases. "Food" appeared together with "desired places" in $63.6 \%$ of cases.

Subsequently, the items comprising each cluster, were summed up together, in order to form larger dimensions. In this way we built 6 quantitative macro-variables: "stories with complicating action-resolution", "verbal interaction", "orientation", "explorative-descriptive", "return" and "travel's pleasures".

Furthermore, we examined the correlation between the macro-variables created. This test showed that the macrovariable "stories with complicating action-resolution" were positively correlated to the "verbal interaction" macrovariable $(\mathrm{r}=.34, p<.01)$ and it was negatively correlated with the macro-variables "explorative-descriptive" ( $\mathrm{r}=-.26$, $p<.05)$ and "travel's pleasures" $(\mathrm{r}=-.41, p<.01)$. The "verbal interaction cluster" was positively correlated with the "orientation" cluster $(\mathrm{r}=.34, p<.01)$.

\subsubsection{Comparison between Cluster Analysis Results in Unlikelihood Narratives and Likelihood Narratives}

Table 5 shows means, standard deviations and Student's T-test results. We examined the differences between unlikelihood and likelihood narratives, as clusters and emotional word elements.

Table 5. Comparison between un-likelihood narratives and likelihood narratives in the cluster elements and emotions.

\begin{tabular}{|c|c|c|c|c|}
\hline \multirow[t]{2}{*}{-} & \multicolumn{2}{|c|}{ Unlikelihood Narratives } & \multicolumn{2}{|c|}{ Likelihood Narratives } \\
\hline & $\mathbf{M}$ & DS & M & DS \\
\hline \multicolumn{5}{|l|}{ Clusters } \\
\hline Stories with complicating action-resolution & 2.07 & 1.76 & .84 & 1.24 \\
\hline Verbal interaction & 1.03 & .87 & .56 & .66 \\
\hline Orientation & 2.00 & 1.23 & 1.96 & .96 \\
\hline Explorative-descriptive & 1.26 & 1.07 & 1.53 & 1.01 \\
\hline Return & 1.03 & 1.11 & 1.53 & 1.16 \\
\hline Travel's pleasures & 1.23 & .99 & 1.37 & 1.09 \\
\hline Emotion words & \multicolumn{2}{|c|}{ Un-likelihood narratives } & \multicolumn{2}{|c|}{ Likelihood narratives } \\
\hline Positive feelings & 2.05 & 1.18 & 2.31 & 1.55 \\
\hline Positive emotions & .48 & .56 & .30 & .60 \\
\hline Optimism & .28 & .45 & .34 & .65 \\
\hline
\end{tabular}


(Table 5) contd.....

\begin{tabular}{|c|c|c|c|c|}
\hline \multirow[t]{2}{*}{-} & \multicolumn{2}{|c|}{ Unlikelihood Narratives } & \multicolumn{2}{|c|}{ Likelihood Narratives } \\
\hline & $\mathbf{M}$ & DS & $\mathbf{M}$ & DS \\
\hline Negative emotions & .90 & .82 & .49 & .60 \\
\hline Anxiety & .08 & .20 & .13 & .32 \\
\hline Anger & .41 & .62 & .13 & .39 \\
\hline Sadness or depression & .27 & .46 & .19 & .38 \\
\hline
\end{tabular}

When comparing "unlikelihood narratives" with "likelihood narratives", it was found that the first ones were characterised by complicating action-resolution elements $(\mathrm{t}=-3.11, p .=<.05)$ and by the presence of verbal interactions $(\mathrm{t}=-2.35, p<.05)$.

An example of an unlikelihood story is the following: " They arrived in New York, but they were on the roof and they saw 4 different coloured turtles. One turtle was blue, another was violet, another red and the last one was orange. They realised that these turtles were ninjas. They almost found a door when....Tigherdum caught Giulio's friend Serena and then he flew away with a rocket rock-sac, but Giulio jumped on him to make him stop and Tigherdum fell down".

An example of likelihood stories is the following: "They saw a big building with many stairs and many workers. And beside it was a huge restaurant with many tables. A museum. And a football stadium, a cheeseburger shop and an ice-cream shop. Then they went on and they found other houses, a zoo and a five-star hotel".

Both fictional and likelihood narrations were equally characterized by the presence of "Orientation", "Descriptions", "Return" and "Travel's pleasures" features.

The analysis of emotional words showed that the unlikelihood narratives, compared to likelihood ones, showed a larger amount of words connected to negative emotions $(\mathrm{t}=-2.16, \mathrm{p}=.034)$ and in particular of those words connected to anger $(\mathrm{t}=-2.11, \mathrm{p}=.039)$. In the following extract, an example of the presence of negative emotions in an unlikelihood story, written by a child, is shown: "[...] and he tells him that behind the mountain there was a monster named Smemerlino! and the child got frightened. But for all the nice things he decided to stay. However bad luck sometimes arrives in life and here the Smemerlino monster comes, all the citizens were scared but the child managed to organise a terrifying prank [...]". There was no evidence of differences connected to the presence of positive emotions in the two types of story.

\section{DISCUSSION}

The main purpose of this work was to investigate the elements that characterise fictional narratives about the exploration of an unknown city, produced by 7 and 8 years old children.

One goal of this exploratory research was to study both realistic and imaginative aspects connected to children's representation of a tourist visit to a city. Therefore, we also aimed to explore the child's representation, connected to the discovery of a new city, in order to have a better comprehension on the children's needs and desires are when connected to travel experiences. Furthermore, understanding how children interpret travel experiences was also a goal of our study. Purposely, we opted for asking children to produce a story starting from a given stem. The narrative tool had great potential to shed light on the children's 'meaning making' processes connected with tourist experiences. The request for fictional stories promoted children's expressive elaboration of expectations and imagination about visiting unknown places.

Thus, to reach the goals of the present study, the style of fictional narratives about a visit to an unknown city has been assessed, as well as the main features of the narrated stories.

We hypothesised, on the basis of scientific literature, in the field of fictional narratives and imagination process, that children narrate their fictional visit according to two main styles: likelihood and unlikelihood. Furthermore, these two styles reproduce two possible points of view regarding the visit to an unknown place, representing different orientations in children's thought. Given the explorative character of this study, we were interested in analysing these two different representations in order to draw suggestions for the creation of specialised tourist services, tailored to children's needs, desires and cognitive characteristics.

A content, structure and lexical analysis on the stories was performed.

The content analysis shows that children's stories about travel in a strange city have the following characteristics: they are mainly descriptive, are shared with friends and concern movement from one place to another, which are mainly desired places such as ice-cream shops or the park. We also found that in many stories the themes of goal achievement 
and the protagonist returning home are present.

Considering the type of stories produced, as hypothesised, our sample showed two major narrative tendency or styles: one group was orientated to a likelihood way of narrating the travel experience and the other group was more orientated to the creation of unlikelihood, made-up, stories.

The likelihood stories are characterised by the presence of play and exploration activities, parents' characters and usually finish with the return to home. Usually, children's tourist experiences take place in the family context and are built around play and explorative activities. These kinds of story seem to follow the rules of the real world and are more similar to the script of a classical visit to a city. This point makes us believe that presumably this type of story is based on an autobiographical memory process. Indeed, every story can be placed in a specific world, which could be either the world that we know, or a "possible world", in which the common laws we know are present [40]. We can suppose that, to construct likelihood stories, children need an amount of knowledge about travelling to a city, which can mainly arise from personal experience. For this reason, likelihood narratives share common features with personal narratives.

The unlikelihood genre, on the other hand, is more based on processes close to imagination and to fairy-tale narratives. In these kinds of stories, children deal with the creation of a possible world, completely imagined by them or inspired, for example, by literature for children.

Furthermore, this genre is characterised by the presence of dangerous elements and villains and fairy tale characters and anthropomorphic animals. In these narratives, children are mainly oriented toward the creation of interesting stories, based on the presence of listener expectations. Coherently with Stein [27] these stories are organised around the content categories of conflict and threat. This evidence suggests to us that in the creation of tailored tourist services for children experts should design paths fulfilling their expectations and including complication and resolution aspects, from one point of interest to another. In their visit experience, children need to find something mysterious and complicated, which activates their motivation to maintain attention and move towards a resolution. In this sense, a tourist visit to a city or a new place could be organised by introducing children to knowledge, following the plot of a story, completed through orientation, complication and resolution.

Furthermore, children deal with the creation of a possible world, completely invented by them or inspired, for example, from media and literature for children, as suggested by the presence of some fairy tale characters in the children's stories that were collected.

This evidence is also suggested by the results of the cluster analysis: children narrate their visit to an unknown place using alternating fantastic and realistic elements, which involve the protagonists partaking in adventures. In the collected narratives, children often combined the intrusion of evil characters, followed by resolutions which close the story, with the triumph of the good character over the evil one, just as described in the narrative plot "Overcoming the monster" [9]. These narratives, moreover, enable the child to test their own problem-solving capacity that leads to a final resolution.

As suggested by cluster 2 in our results, children consider the presence of fairy-tale characters to be important as they play the role of helper for the protagonist.

Furthermore, narratives often describe adventures involving the protagonist achieving some goals or victories. These moments were sometimes represented as the victory over an enemy, others times the achievement of a reward or a prize, such as, for example, being declared king or major.

Since the collected stories have a strong imaginative component, closely related to existing genres, this suggests to us to insert in the tourist visit themes connected to mystery, magic and the fairy-tale world. This can be represented by the reading of a legend connected to the place or by the appearance of actors performing fairy-tale characters and so on.

Moreover, challenges seem to be a strong motivational element in the children's life and therefore the visit can contain an occasion to complete a challenge in a safe, controlled, but not-ordinary, context. In this sense, tourist operators could offer problem-solving activities, competitions, games and so on, remembering however, that children like challenges but hate to lose.

Another interesting result is the frequent reference in narratives to the return home of the protagonist. This is a typical theme present in almost every travel narrative. As Ithaca for Ulysses, the return to the family of the protagonist represents for children the right ending of travel, marked by the strong component of growth and discovery.

Furthermore, in likelihood stories, descriptions of places are detailed with particular attention to the aspects of the 
senses such as colours, sizes or tastes.

To summarise, the presence of likelihood elements in the stories about an unknown place suggests to us the need to take into consideration the importance of keeping a connection between past knowledge and the personal memories of children, when facing new places. In other words, in their narratives children express from one side, their need to enter into the world of possibility, searching for something adventurous and unexpected. From the other side, they need to refer to what is consolidated, and to connect the new experiences with their knowledge on the world and their past, saving the opportunity to come back home at the end of the visit. In this sense, tourist operators could save a space for children's memories and previous knowledge, when introducing unknown places to them.

The continuum between personal experiences and fictional elements in collected narratives, as well as between possible and not-possible, seems to be connected to the cognitive processes involved in imaginative activity. As we have learnt from Vygotsky's works [17], the two basic types of human activities are related to reproductive and creative behaviours. These two activities are mutually connected: the imagination process "combines and creatively reworks elements of this past experience and uses them to generate new propositions and new behaviour" (p. 9). Similarly, Zittoun and Cerchia [40] argued that the imagination process could be viewed as an expansion of human experience. In other words, in their fictional narratives children have expanded their knowledge of known places to their imagination and wonder about unknown cities. In this process, and by means of narrative proprieties, their visitor experiences have acquired the characteristics of an adventure in which complications and resolutions leaded them to the discovery of a new city.

Furthermore, the narrative plot implies a strong emotional and affective involvement.

The need for an affective experience is therefore described by the analysis of emotional words in the narratives. In fact, the lexical analysis of emotional words shows that fantasy stories, compared to the realistic ones, are mostly characterised by the presence of negative emotions and in particularly anger. This is probably connected to the appearance in the story of complicating actions and evil characters. Thus, children need both positive and negative emotional involvement when visiting a new place, alternating fantastic and adventurous elements with realistic and known ones.

\section{CONCLUSION}

In conclusion we can claim that narration is a potential instrument to give meaning to the travel experience and to further enhance the imagination of future ones. When children imagine travel experiences, some of them pick up elements from their personal experiences, whereas others use more imaginative features.

\section{ETHICS APPROVAL AND CONSENT TO PARTICIPATE}

Not applicable.

\section{HUMAN AND ANIMAL RIGHTS}

No animals/humans were used for studies that are the basis of this research.

\section{CONSENT FOR PUBLICATION}

Not applicable.

\section{CONFLICT OF INTEREST}

The authors declare no conflict of interest, financial or otherwise.

\section{ACKNOWLEDGEMENTS}

The present work arises in the context of CAB project which is co-financed under Tuscany Por FESR 2014-2010 (D. N. 3389 of the 30/07/2014). The aim of this project is to realize a technological appli-cation for handheld devices, that allow children to have an active position in touristic experience. 

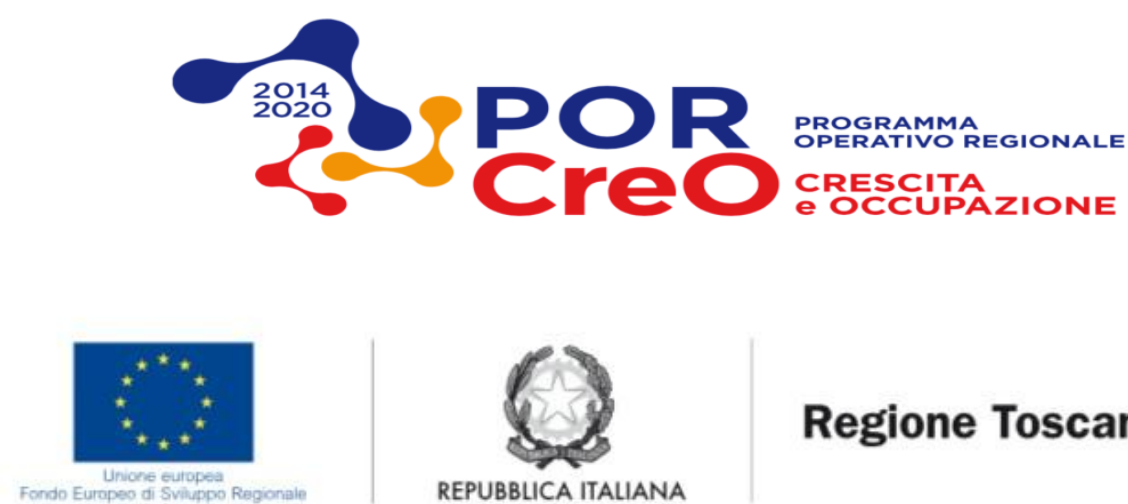

Regione Toscana

REPUBBLICA ITALIANA

\section{REFERENCES}

[1] Schänzel H, Yeoman I, Backer E, Eds. Family Tourism: Multidisciplinary Perspectives. Bristol: Channel View 2012.

[2] Bakir A, Rose GM, Shoham A. Family communication patterns: Mothers' and Fathers' communication style and children's perceived influence in family decision making. J Int Consum Mark 2006; 19(2): 75-95. [http://dx.doi.org/10.1300/J046v19n02_05]

[3] Sharma A, Sonwaney V. Theoretical modeling of influence of children on family. Purchase decision making. Procedia. Soc Behav Sci 2014; 133(15): 38-46.

[4] Lehto XY, Choi S, Lin YC, MacDermid SM. Vacation and family functioning. Ann Tour Res 2009; 36(3): $459-79$. [http://dx.doi.org/10.1016/j.annals.2009.04.003]

[5] Pearce PL, Stringer PF. Psychology and tourism. Ann Tour Res 1991; 18(1): 136-54. [http://dx.doi.org/10.1016/0160-7383(91)90044-C]

[6] Small J. The absence of childhood in tourism studies. Ann Tour Res 2008; 35(3): 772-89. [http://dx.doi.org/10.1016/j.annals.2008.06.002]

[7] Stone MJ, Petrick JF. The educational benefits of travel experiences: A literature review. J Travel Res 2013; 1-14.

[8] Gamradt J. Jamaican children's representations of tourism. Ann Tour Res 1995; 4: 735-62. [http://dx.doi.org/10.1016/0160-7383(95)00024-7]

[9] Booker CC. The seven basic plots: Why we tell stories. London: Continuum Publishing Group 2004.

[10] Bruner JS. Acts of meaning. Cambridge: Harvard University Press 1990.

[11] Riva F. Filosofia del viaggio. Roma: Castelvecchi 2013.

[12] McCabe A, Peterson C. Getting the story: A longitudinal study of parental styles in eliciting narratives and developing narrative skill.Developing narrative structure. Hillsdale, NJ: Erlbaum 2008; pp. 217-53.

[13] Hudson JA, Shapiro LR. From knowing to telling: The development of children's scripts, stories, and personal narratives Developing narrative structure. 1991.

[14] Ukrainetz TA, Justice LM, Kaderavek JN, Eisenberg SL, Gillam RB, Harm HM. The development of expressive elaboration in fictional narratives. J Speech Lang Hear Res 2005; 48(6): 1363-77.

[http://dx.doi.org/10.1044/1092-4388(2005/095)] [PMID: 16478377]

[15] Demorest AP, Alexander IE. Affective scripts as organizers of personal experience. J Pers 1992; 60(3): 645-63. [http://dx.doi.org/10.1111/j.1467-6494.1992.tb00924.x]

[16] Peterson C, McCabe A. Developmental psycholinguistics: Three ways of looking at a child's narratives. New York: Plenum Press 1983. [http://dx.doi.org/10.1007/978-1-4757-0608-6]

[17] Vygotsky LS. Imagination and creativity in childhood. J Russ East Eur Psychol 2004; 42(1): 7-97. [http://dx.doi.org/10.1080/10610405.2004.11059210]

[18] Pelaprat E, Cole M. "Minding the gap": Imagination, creativity and human cognition. Integr Psychol Behav Sci 2011; 45 (4): $397-418$. [http://dx.doi.org/10.1007/s12124-011-9176-5] [PMID: 21695391]

[19] Stone SJ, Stone W. Symbolic play and emergent literacy, in Brno conference, International Council for Children's Play, Eds . 2007.

[20] Pellegrini AD, Galda L. Ten years after: A re-examination of symbolic play and literacy research. Read Res Q 1993; $163-75$.

[21] Schacter DL, Addis DR. The cognitive neuroscience of constructive memory: Remembering the past and imagining the future. Philos Trans R Soc Lond B Biol Sci 2007; 362(1481): 773-86.

[http://dx.doi.org/10.1098/rstb.2007.2087] [PMID: 17395575] 
[22] D'Argembeau A, Van der Linden M. Phenomenal characteristics associated with projecting oneself back into the past and forward into the future: Influence of valence and temporal distance. Conscious Cogn 2004; 13(4): 844-58. [http://dx.doi.org/10.1016/j.concog.2004.07.007] [PMID: 15522635]

[23] Labov W. Some Further steps in narrative analysis. J Narrat Life Hist 1997; 7(1-4): 395-415. [http://dx.doi.org/10.1075/jnlh.7.49som]

[24] Labov W, Waletzky J. Narrative analysis: Oral versions of personal experience. Washington: University of Washington Press 2003.

[25] Gruendel JM. Scripts and stories: A study of children's event narratives. 1980.

[26] Peterson C, McCabe A. Understanding "because": How important is the task? J Psycholinguist Res 1985; 14(2): 199-218. [http://dx.doi.org/10.1007/BF01067629]

[27] Stein NL. The development of children's storytelling skill.Child language: A Reader. New York: Oxford University Press 1988.

[28] Bruner JS. Making stories: Law, literature, life. Harvard University Press 2003.

[29] Lansky LM. Story completion methods.projective techniques in personality assessment. Berlin: Springer 1968.

[30] Colby B. A partial grammar of Eskimo folktales. Am Anthropol 1973; 75: 195-201. [http://dx.doi.org/10.1525/aa.1973.75.3.02a00010]

[31] Sutton-Smith B, Botvin G, Mahony D. Developmental structures in fantasy narratives. Hum Development 1976; $19: 1$-13. [http://dx.doi.org/10.1159/000271510]

[32] Botvin GN, Sutton-Smith B. The development of structural complexity in children's fantasy narratives. Dev Psychol 1977; 13: 377-88 [http://dx.doi.org/10.1037/0012-1649.13.4.377]

[33] Labov W. Language in the Inner City. Philadelphia, Pa.: University of Pennsylvania Press 1972.

[34] Propp W. Morphology of the Folktale. Austin: University of Texas Press 1968.

[35] Labov W, Cohen P, Robins C, Lewis J. 1968.A study of the non-standard English of Negro and Puerto Rican speakers in New York City.

[36] Labov W. Oral narratives of personal experience. 2010.

[37] Li CN. Direct and indirect speech: A functional study. In: Coulmas F, Ed. Direct and indirect speech. Berlin: Walter de Gruyter \& Co 1986. [http://dx.doi.org/10.1515/9783110871968.29]

[38] Pennebaker JW, Francis ME, Booth RJ. Linguistic Inquiry and Word Count (LIWC): A Computerized Text Analysis Program. Mahwah: Erlbaum Publishers 2001.

[39] Smorti A. Narrazioni: Cultura, memorie e formazione del sé. Firenze: Giunti Editore 2007.

[40] Zittoun T, Cerchia F. Imagination as expansion of experience. Integr Psychol Behav Sci 2013; 47(3): $305-24$. [http://dx.doi.org/10.1007/s12124-013-9234-2] [PMID: 23625542]

\section{(C) 2018 Della Croce et al.}

This is an open access article distributed under the terms of the Creative Commons Attribution 4.0 International Public License (CC-BY 4.0), a copy of which is available at: (https:/creativecommons.org/licenses/by/4.0/legalcode). This license permits unrestricted use, distribution, and reproduction in any medium, provided the original author and source are credited. 